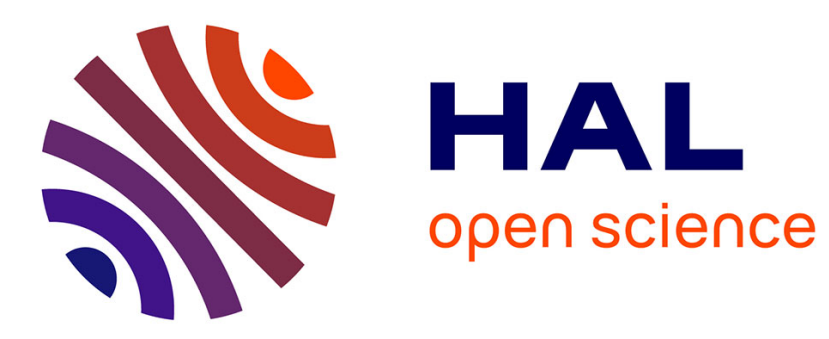

\title{
Lateral inventory transshipment problem in online-to-offline supply chain
}

Fuguo Zhao, Desheng Wu, Liang Liang, Alexandre Dolgui

\section{To cite this version:}

Fuguo Zhao, Desheng Wu, Liang Liang, Alexandre Dolgui. Lateral inventory transshipment problem in online-to-offline supply chain. International Journal of Production Research, 2016, 54 (7), pp.19511963. 10.1080/00207543.2015.1070971 . emse-01184880

\section{HAL Id: emse-01184880 \\ https://hal-emse.ccsd.cnrs.fr/emse-01184880}

Submitted on 7 May 2021

HAL is a multi-disciplinary open access archive for the deposit and dissemination of scientific research documents, whether they are published or not. The documents may come from teaching and research institutions in France or abroad, or from public or private research centers.
L'archive ouverte pluridisciplinaire HAL, est destinée au dépôt et à la diffusion de documents scientifiques de niveau recherche, publiés ou non, émanant des établissements d'enseignement et de recherche français ou étrangers, des laboratoires publics ou privés. 


\title{
Lateral inventory transshipment problem in online-to- offline supply chain
}

\author{
Fuguo Zhao, Desheng Wu, Liang Liang \& Alexandre Dolgui \\ International Journal of Production Research \\ Volume 54, 2016 - Issue 7, pages 1951-1963 \\ https://doi.org/10.1080/00207543.2015.1070971
}

\begin{abstract}
Online-to-Offline (OTO) is a new commercial model with enormous market potential. Online customer orders are forwarded to the offline brick-and-mortar store to fulfill, which is a combination of dual-channel supply chain. OTO overcomes many disadvantages of the traditional dual-channel supply chain, but still faces uncertain market demand. To reduce the inventory risk caused by demand uncertainty, lateral inventory transshipment is employed in this paper to pool inventory risk in OTO supply chain. We model centralized OTO and decentralized OTO with/without transshipment, and then analyze different scenarios. Our results demonstrate that there exists a unique Nash equilibrium of inventory order levels in dual channels and an optimal transshipment price to maximize the profit of the entire supply chain. Finally, we provide a numerical example of uniform demand distribution. Our analyses offer many managerial insights and show that transshipment always benefits the OTO supply chain.
\end{abstract}

Keywords: Inventory Transshipment, Online-to-Offline (OTO), Dual-channel Supply Chain, Demand Uncertainty

Received 09 Dec 2014, Accepted 17 Jun 2015, Published online: 30 Jul 2015

alexandre.dolgui@imt-atlantique.fr 


\section{Introduction}

The rapid development of commerce on the Internet has made the link between online and physical commerce stronger, which leads many companies to consider engaging in direct sales (Chiang et al. 2003). Dual-channel supply chain benefits customers by providing additional purchasing choices. Consumers will balance the related advantages and disadvantages of the two channels in their purchasing decisions. For example, buying from the retail channel offers instant gratification, customers can experience the goods first which can reduce the possibility of sales return due to product defect or delivery damage. However, consumers need to spend money, time and effort to go to a brick-and-mortar store, and may face a stockout. Whereas the direct online channel provides availability of online information about substitutable products, and sometimes lower price, but requires delivery lead time (Chen et al. 2008, Huang et al. 2012). Dual-channel supply chain brings a direct competitor of any existing retailers, which results in "channel conflict" (Tsay and Agrawal, 2004).

Drop shipping is employed by dual-channel supply chain as an order fulfillment strategy. In this model, retailers do not own inventory, and simply forward customer orders to the manufacturer. The manufacturer keeps inventory and fulfills those orders directly to the customers with a predetermined price to be paid by the retailers. Drop-shipping has some advantages compared with the traditional dual-channel supply chain model in which retailers hold inventory. Retailers can reduce inventory costs, transportation costs and under-stock cost, while manufacturer can increase sales and reduce advertising costs. Under the drop-shipping arrangement, the supply chain benefits from inventory risk pooling because all the inventories are stocked at the manufacturer's warehouse. However, customers will suffer long delivery time and cannot experience the product in advance, sometimes even face product unavailability because of the manufacturer's stockout (Ayanso et al. 2006).

To overcome the shortcomings of traditional dual-channel supply chain and drop-shipping model, in this paper, we study a new business model named Online-to-Offline (OTO). The manufacturer (referred as "he" throughout this paper) owns an e-store as a direct channel to sell the product, and forwards customer orders to the retailer (referred as "she" throughout this paper) who 
is the nearest to the customer. The manufacturer pays a preset unit revenue share to the retailer for fulfilling every direct channel's customer order. In this way, the delivery lead time is shorter than e-store delivers directly. Customers can also go to the nearest retailer to pick up the product, and experience in advance on the spot. OTO is a good combination of retail channel and direct channel. The similarities and differences of the three models aforementioned are listed in Table 1.

Table 1. The differences and similarities of the three supply chain models

\begin{tabular}{|c|c|c|}
\hline Models & Differences & Similarities \\
\hline $\begin{array}{l}\text { Traditional dual-channel } \\
\text { supply chain }\end{array}$ & $\begin{array}{l}\text { Customer orders in each channel are } \\
\text { fulfilled by themselves, separately. }\end{array}$ & \\
\hline Drop-shipping model & $\begin{array}{l}\text { Retailers do not own inventory, and all } \\
\text { customer orders are fulfilled by the } \\
\text { manufacturer. }\end{array}$ & $\begin{array}{l}\text { All the three models consist of a } \\
\text { direct channel and a retail }\end{array}$ \\
\hline OTO supply chain & $\begin{array}{l}\text { The manufacturer does not own } \\
\text { inventory, and customer orders are } \\
\text { fulfilled by the retailer who is the } \\
\text { nearest to the customer. It can reduce } \\
\text { the delivery cost and lead time. }\end{array}$ & offline channel. \\
\hline
\end{tabular}

In an OTO supply chain, the retailer orders based on the predicted retail channel's demand in advance of the selling season, then the manufacturer fulfills the retailer's order, plus his own inventory according to the predicted direct channel's demand. The manufacturer bears no inventory risk which is contrary to drop-shipping, but he needs to pay the inventory cost for his own inventory.

Inventory transshipment is a powerful mechanism to monitor movement of products among locations at the same echelon. It matches supply and demand by transshipping excess stock of one member to another with insufficient stock, thus reduces inventory costs and improves service level (Belgasmi et al. 2008). The OTO supply chain employs virtual transshipments where all the inventories are stored at the retailer's warehouse. It bears no transshipment cost and reduces the stockout risk of both parties.

The last decade has witnessed wide practical applications of OTO supply chain. According to some scholars and practitioners, OTO bring about widespread availability of online information 
about substitutable products, suppliers, and pricing for customers. Qumei Furniture is a large furniture company in China who owns about 600 retail stores in more than 200 cities. Charging the same price in both channels, Qumei Furniture employs OTO strategy to fulfill customer demands. Qumei's e-store forwards the online order to the retail store who is the nearest to the customer to deliver. Since furniture is usually very large, OTO can reduce the delivery cost and delivery time remarkably.

The market potential of OTO is tremendous. It is very prevalent in many industries, for example, appliance, education, clothing, hotels and catering. OpenTable, Groupon and Restaurant.com are three large group-buying websites who sell discounted meals online and bring customers into brick-and-mortar restaurants to consume. Wowo Ltd. is an e-commerce company that employs OTO model to provide life services in China. It has been successfully listed on a US Nasdaq exchange in 2015. Wowo provides a platform that attracts customers to order and pay for products and services online, and forwards the orders to offline brick-and-mortar store to fulfill.

OTO benefits both the manufacturer and the retailer. To the best of our knowledge, this paper is the first one that describes and analyzes OTO supply chain model. The rest of this paper is organized as follows. Section 2 outlines the related literature. Section 3 models and analyzes the centralized OTO and decentralized OTO with/without inventory transshipment. Section 4 presents a numerical example with uniform demand distribution and provides more managerial insights. Conclusions and future research areas are summarized in Section 5.

\section{Literature review}

There are two streams of research closely related to our model. The first stream of literature focuses on drop-shipping supply chain. Research on how to achieve coordination in dual-channel supply chain has received considerable attention. Drop-shipping, where the manufacturer own inventory and delivers the product directly to customers at retailers' request, is usually adopted to pool inventory risk and reduce inventory cost.

Yao et al. (2008) analyzed a drop-shipping distribution system comprising an e-retailer and a supplier. They addressed whether and when the supplier is willing to share its private cost 
information with the e-retailer. Rabinovich et al. (2008) investigated internet retailing in a drop-ship context. Their results suggested that an e-retailer can obtain higher margins from online customers when it provides more favorable physical distribution service. Gan et al. (2010) proposed a commitment-penalty contract in a drop-shipping supply chain with asymmetric demand information, and showed that the contract guaranteed the supplier to obtain the retailer's demand information. Khouja and Stylianou (2009) developed two (Q, R) inventory models that allow a retailer to use the drop shipping option in case of a shortage during lead time. Khouja (2001) designed an optimal mix strategy which captures the advantages of drop shipping and avoids many of its shortcomings. Hovelaque et al. (2007) identified three inventory models, i.e., store-picking, warehouse-picking and drop-shipping, in a dual-channel supply chain. Their analyses showed that without taking transport costs and fixed costs into consideration, retailer profits in the store-picking or dropshipping models are greater than in the warehouse-picking scenario. Ayanso et al. (2006) studied a threshold level inventory rationing policy where an e-retailer uses drop-shipping to fulfill the stochastic demand of made-to-stock products. Randall et al. (2006) compared the effect of dropshipping with the traditional channel on firm's performance, and studied the conditions when to employ drop-shipping to fulfill orders.

There exists a rich literature on models of transshipment. Paterson et al. (2011) provided a literature review which categorizes the research on lateral transshipment. Much of transshipment literature focuses on two locations, see Rudi et al. (2001), Tagaras and Vlachos (2002), Zou et al. (2010), and Hezarkhani and Kubiak (2010); multilocations, see Robinson (1990), Archibald et al. (2009), Paterson et al. (2012), and Özdemir et al. (2013); and transshipment networks, see Lien et al. (2011) and Yu et al. (2011). Rudi et al. (2001) studied a transshipment case of two locations being individually owned and operated situation by two sellers, where a location has surplus stock and another location is stocked out. They examined how transshipment affects the optimal inventory orders at each location. Dong and Rudi (2004) discussed the effects of transshipment on manufacturer and retailer, considering both exogenous and endogenous wholesale prices. Zhang (2005) extended Dong and Rudi (2004) to general demand distributions, and studied the impact of transshipment by comparing the adjusted demand with the normal distribution demand. Li and Zhang (2012) studied a two-location inventory system with transshipment to obtain risk pooling, 
and their results showed that the risk pooling improves the service levels at both locations. Netessine and Rudi (2006) modeled the dual strategy as a noncooperative game among the retailers and the wholesaler. They specified appropriate ranges of critical parameters to characterize situations in which each of the three channels is preferable. Chen et al. (2012) explored a two-echelon supply chain with one supplier and two retailers in two periods. They demonstrated that there exists a unique optimal distribution policy for maximizing the overall expected profit of the supply chain, and the transshipment benefits both supplier's and retailers' optimal expected profit. Belgasmi et al. (2008) proposed a multiobjective model of multi-location transshipment problem, considering a multi-location inventory system where inventory choices at each location are centrally coordinated.

The transshipment studies aforementioned are conducted in the noncapacitated context. $\mathrm{Hu}$ et al. (2007) considered a two-location production/inventory model where each location makes production decisions and is subject to uncertain capacity. They explored the conditions when coordinating prices exist and the effects of demand and capacity variability on transshipment prices. Yang and Qin (2007) studied the virtual lateral transshipment optimal control of a two-location capacitated manufacturing plants model. They found that each plant should employ a modified basestock strategy to observe its own capacity, and the base level decreases in the other plant's starting inventory level. Hu et al. (2008) explored the effects of capacity uncertainty on the optimal joint control of inventory and transshipment for a firm that produces in two locations. They characterized the optimal production and transshipment policies and studied how the uncertain capacity leads to counterintuitive behavior and inventory rationing policy. Özdemir et al. (2013) incorporated replenishment capacity into the traditional lateral transshipment model. They analyzed the impact of failing to fulfill all the replenishment orders on stocking locations' performance. Their results showed that the service level depends on capacity flexibility and transshipment flexibility. Our study investigates the OTO supply chain model, which incorporates lateral transshipment and enriches transshipment literature.

\section{Model}

Consider a dual-channel supply chain consisting of one manufacturer (m) and one retailer (r). The manufacturer manages an e-store (e) to sell a product through direct channel and employs OTO 
strategy to fulfill customer orders. The manufacturer produces the product at unit manufacturing cost $c$ and sells to the retailers at unit wholesale price $w$. The product is sold in both channels at price $p$, every unsold unit has salvage value $s$, and every unit of unmet demand incurs penalty cost $l$. The manufacturer gives the retailer a revenue share $r$ for fulfilling every unit direct channel's order. We denote $D_{i}(i=r, e)$, as the demand of store $i$ for the product, with probability distribution function (PDF) of $f_{i}(\cdot)$, cumulative distribution function (CDF) of $F_{i}(\cdot)$ which are continuous and differentiable, on its support, respectively, and $F_{i}^{-1}(\cdot)$ as the inverse function. Since all the customers receive the product from the retailer with the same selling price, it is reasonable to assume there is no customer switching between the two channels, and $D_{r}$ and $D_{e}$ are independent (Dodd, 2001; Seifert et al., 2006; He et al., 2014). Table 2 lists the notations for key parameters and variables in the model. We ignore the inventory holding cost and delivery cost, which just bring extra parameters, but without introducing any additional insights. Figure 1 illustrates the typical OTO supply chain structures.

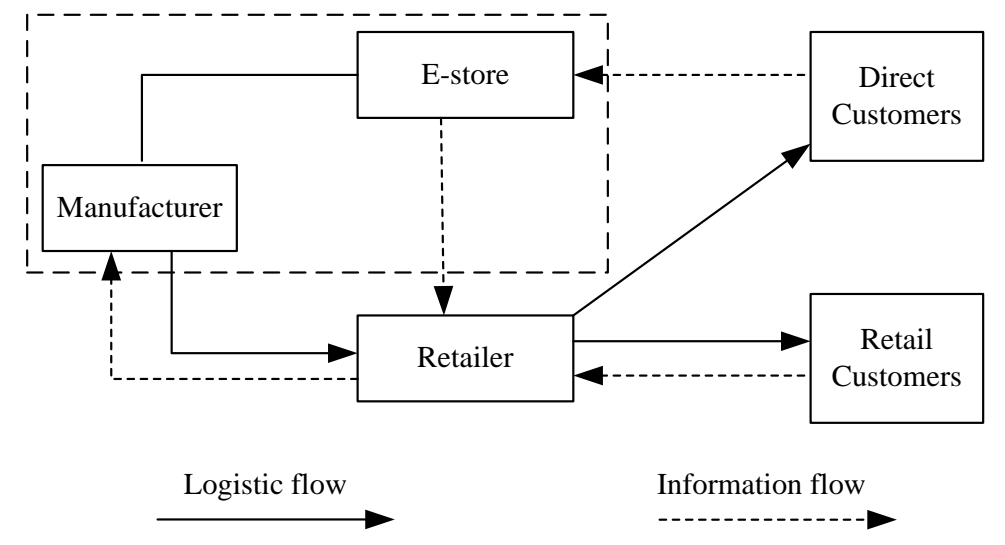

Figure 1. Online-to-Offline supply chain structures.

Table 2. Notations of key parameters and variables in the model.

\begin{tabular}{cl}
\hline Notation & Definition \\
\hline$c$ & unit manufacturing cost \\
\hline
\end{tabular}




$\begin{array}{ll}w & \text { unit wholesale price } \\ p & \text { unit selling price } \\ r & \text { share (percent) of the revenue for OTO } \\ s & \text { salvage value for unit of unsold stock } \\ l & \text { penalty cost for unit unmet demand } \\ \tau & \text { unit transshipment price } \\ T_{i j} & \text { the transshipment quantities from store } i \text { inventory to store } j, i, j=r, e, i \neq j \\ U_{i} & \text { the unsold stock quantity of store } i \\ V_{i} & \text { the unmet demand of store } i \\ D_{i} & \text { predicted market demand in store } i \\ \pi_{i}^{k} & \text { inventory order level for store } i, \text { a decision variable } \\ \pi_{i}^{N} & \text { expected profit of store } i \text { with transshipment in decentralized OTO supply chain } \\ & \end{array}$

To avoid trivialities, we present the following assumptions:

(a) $0<r<p-w .0<r$ ensures the retailer participate in OTO and $r<p-w$ ensures the retailer still order from the manufacturer, i.e., retail profit is more than the revenue share in OTO consignment.

(b) $s<c<w<p . \quad s<c$ rules out the manufacturer producing infinite amount, and $s<w$ rules out the possibility of the retailer ordering infinite amount; $c<w$ for the manufacturer to be beneficial and $w<p$ for the retailer to be beneficial. 
(c) $s<\tau<p+l-r$. The two terms ensure transshipment to be beneficial to both the retailer and the manufacturer when they face inventory overage or underage, respectively.

\subsection{Centralized OTO Supply Chain}

In the centralized supply chain, the manufacturer owns both the brick-and-mortar retailer and eretailer which can be considered as a strategic alliance (e.g., Qumei, restaurant.com) or the retailer owns a traditional retail channel and an e-retail channel (e.g., Gome, Suning). The decision maker decides the optimal order quantity on the basis of total market demand to maximize the entire supply chain profit. Define $(x)^{+}=\max \{x, 0\}$, the expected profit of the entire supply chain $\pi^{C}$ is

$$
\pi^{C}=p \operatorname{Emin}(D, Q)+s E(Q-D)^{+}-l E(D-Q)^{+}-c Q
$$

where $D=D_{e}+D_{r}$ and $Q=Q_{e}+Q_{r}$. Taking the first derivative of (1) with respect to $Q$, the following expression holds.

$$
\frac{\partial \pi^{C}}{\partial Q}=p P(D>Q)+s P(D<Q)+l P(D>Q)-c
$$

Letting (2) equal to zero and rearranging results, the optimal order quantity satisfies

$$
Q^{C^{*}}=F_{D}^{-1}\left(\frac{p+l-c}{p+l-s}\right)
$$

where $F_{D}^{-1}(\cdot)$ is the averse distribution function of total market demand $D$. The superscript "*” is used throughout the paper to indicate optimal parameter values.

\subsection{Decentralized OTO Supply Chain without Transshipment}

In this section, we assume there is no inventory transshipment between the two members in the decentralized OTO supply chain. Their inventories are stored at the retailer's, separately. Under no transshipment, the retailer's and the manufacturer's expected profits are given by

$$
\pi_{m}^{N}=E\left[(p-r) \min \left(D_{e}, Q_{e}^{N}\right)+s\left(Q_{e}^{N}-D_{e}\right)^{+}-l\left(D_{e}-Q_{e}^{N}\right)^{+}\right]+w Q_{r}^{N}-c\left(Q_{r}^{N}+Q_{e}^{N}\right)
$$




$$
\pi_{r}^{N}=E\left[p \min \left(D_{r}, Q_{r}^{N}\right)+r \min \left(D_{e}, Q_{e}^{N}\right)+s\left(Q_{r}^{N}-D_{r}\right)^{+}-l\left(D_{r}-Q_{r}^{N}\right)^{+}\right]-w Q_{r}^{N}
$$

From the results of newsvendor model, the optimal order quantities for the two channels can be written as

$$
\begin{aligned}
F_{e}\left(Q_{e}^{N^{*}}\right) & =\frac{p-r+l-c}{p-r+l-s} \\
F_{r}\left(Q_{r}^{N^{*}}\right) & =\frac{p+l-w}{p+l-s}
\end{aligned}
$$

Proposition 1. In a decentralized OTO supply chain without transshipment, the e-store's optimal order quantity $Q_{e}^{N^{*}}$ is decreasing in revenue share $r$, but irrelevant to the wholesale price $w$; the retailer's optimal order quantity $Q_{r}^{N^{*}}$ is decreasing in $w$, but has nothing to do with $r$.

All the proofs are given in the appendix.

Proposition 2. The total order quantity in decentralized OTO supply chain without transshipment is less than that in centralized OTO supply chain. i.e, $Q_{e}^{N^{*}}+Q_{r}^{N^{*}}<Q^{C^{*}}$.

Since $Q_{e}^{N^{*}}+Q_{r}^{N^{*}}<Q^{C^{*}}$, there exists double marginalization in the decentralized OTO supply chain without transshipment which results in that the total profits of the two parties do not reach the full profit potential of a fully coordinated supply chain (Koulamas , 2006).

\subsection{Decentralized OTO Supply Chain with Transshipment}

In this section, we consider the scenario in which inventories can be transshipped between the two members of supply chain. When one party is stockout, he/she can use the inventories of another party if another party has surplus inventories. The transshipment quantity from store $i$ inventory to store $j$ is $T_{i j}=\min \left(\left(Q_{i}-D_{i}\right)^{+},\left(D_{j}-Q_{j}\right)^{+}\right)$, where $(i, j)=\{(e, r),(r, e)\}$. The unsold stock is $U_{i}=\left(\left(Q_{i}-D_{i}\right)^{+}-\left(D_{j}-Q_{j}\right)^{+}\right)^{+}$and the unmet demand is $V_{i}=\left(\left(D_{i}-Q_{i}\right)^{+}-\left(Q_{j}-D_{j}\right)^{+}\right)^{+}$. The six scenarios of two channels' demands are depicted in Figure 2. 


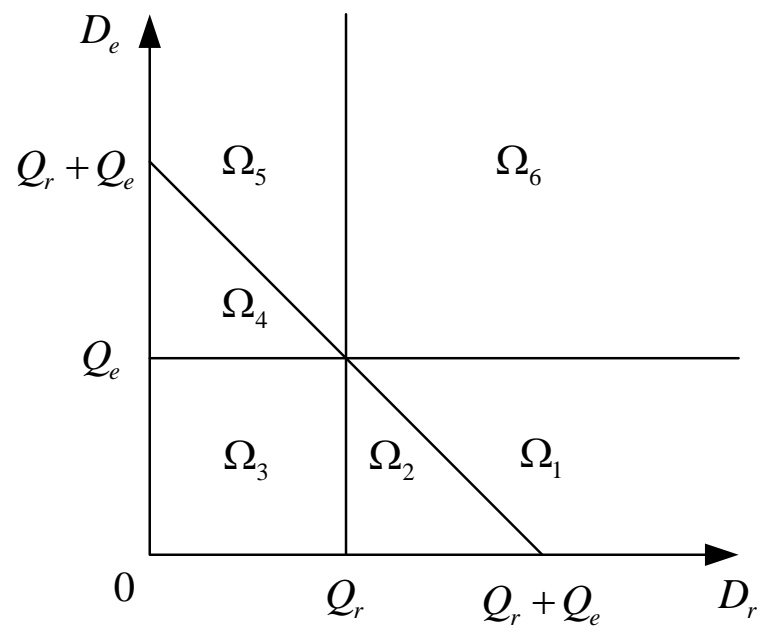

Figure 2. Six possible scenarios of the demand space $\left\{D_{r}, D_{e}\right\}$.

The expected profit functions of the manufacturer and the retailer in an OTO supply chain with transshipment can be expressed as

$$
\begin{aligned}
& \pi_{m}^{T}\left(Q_{e}^{T}, Q_{r}^{T}\right)=E\left[(p-r) \min \left(D_{e}, Q_{e}^{T}\right)+\tau T_{e r}+(p-\tau-r) T_{r e}+s U_{e}-l V_{e}\right]+w Q_{r}^{T}-c\left(Q_{r}^{T}+Q_{e}^{T}\right) \\
& \pi_{r}^{T}\left(Q_{r}^{T}, Q_{e}^{T}\right)=E\left[p \min \left(D_{r}, Q_{r}^{T}\right)+r \min \left(D_{e}, Q_{e}^{T}\right)+(\tau+r) T_{r e}+(p-\tau) T_{e r}+s U_{r}-l V_{r}\right]-w Q_{r}^{T}
\end{aligned}
$$

The two members make inventory decisions to maximum their own profit, so we first take the derivative of the expected profits in (8) with respect to $Q_{e}^{T}$, and obtain

$$
\frac{\partial \pi_{m}^{T}}{\partial Q_{e}^{T}}=\tau P\left(\Omega_{1} \cup \Omega_{4}\right)+s P\left(\Omega_{2} \cup \Omega_{3}\right)+(p-r+l) P\left(\Omega_{5} \cup \Omega_{6}\right)-c
$$

The above equation provides the expected marginal profitability of increasing the inventory ordering level for store $e$. The first term represents that, in Scenario $\Omega_{1}$, the marginal revenue of increasing the inventory level is $\tau$ when store $e$ 's inventory overage is all used to fill store $r$ 's inventory underage without leftover; while in Scenario $\Omega_{4}$, marginal unit of store $e$ 's inventory can reduce opportunity cost $\tau$ of transshipment from store $r$. The second term denotes store $e$ 's inventory overage is used to satisfy store $r$ 's inventory underage but still has leftover. Marginal unit of inventory incurs salvage value $s$. The third term means that the marginal unit of store $e$ 's 
inventory yields $p-r$ revenue and reduces $l$ opportunity loss when either $\Omega_{5}$ or $\Omega_{6}$ happens. At last, the marginal cost of increasing inventory stock is the cost of the product $c$.

Taking the derivative of the expected profits in (9) with respect to $Q_{r}^{T}$, yields the expected marginal profit of an additional unit inventory at store $r$

$$
\frac{\partial \pi_{\mathrm{r}}^{T}}{\partial Q_{r}^{T}}=(p+l) P\left(\Omega_{1} \cup \Omega_{6}\right)+\tau P\left(\Omega_{2}\right)+(\tau+r) P\left(\Omega_{5}\right)+s P\left(\Omega_{3} \cup \Omega_{4}\right)-w
$$

The meaning of Equation (11) closely follows (10). We denote $\alpha_{i}\left(Q_{i}\right)=P\left(D_{i} \leq Q_{i}\right)$, $\beta_{i}\left(Q_{i}, Q_{j}\right)=P\left(Q_{i}+Q_{j}-D_{j}<D_{i} \leq Q_{i}\right)$ and $\gamma_{i}\left(Q_{i}, Q_{j}\right)=P\left(Q_{i} \leq D_{i}<Q_{i}+Q_{j}-D_{j}\right)$, and present the descriptions and probabilities of the six demand areas in Table 3.

Table 3. Descriptions of six scenarios and corresponding probabilities.

\begin{tabular}{cll}
\hline Scenario & Demand area description & Probability \\
\hline$\Omega_{1}$ & $Q_{r}+Q_{e}-D_{r}<D_{e} \leq Q_{e}$ & $\beta_{e}\left(Q_{e}, Q_{r}\right)$ \\
$\Omega_{2}$ & $Q_{r}<D_{r} \leq Q_{r}+Q_{e}-D_{e}$ & $\gamma_{r}\left(Q_{r}, Q_{e}\right)$ \\
$\Omega_{3}$ & $\mathrm{D}_{r}<Q_{r}, D_{e} \leq Q_{e}$ & $\alpha_{e}\left(Q_{e}\right)-\beta_{e}\left(Q_{e}, Q_{r}\right)-\gamma_{r}\left(Q_{r}, Q_{e}\right)$ \\
$\Omega_{4}$ & $Q_{e}<D_{e} \leq Q_{r}+Q_{e}-D_{r}$ & $\gamma_{e}\left(Q_{e}, Q_{r}\right)$ \\
$\Omega_{5}$ & $Q_{r}+Q_{e}-D_{e}<D_{r} \leq Q_{r}$ & $\beta_{r}\left(Q_{r}, Q_{e}\right)$ \\
$\Omega_{6}$ & $\mathrm{D}_{r} \geq Q_{r}, D_{e}>Q_{e}$ & $1-\alpha_{r}\left(Q_{r}\right)-\beta_{e}\left(Q_{e}, Q_{r}\right)-\gamma_{r}\left(Q_{r}, Q_{e}\right)$ \\
\hline
\end{tabular}

From the definition in Table 2, we know

$\alpha_{r}\left(Q_{r}\right)-\beta_{r}\left(Q_{r}, Q_{e}\right)+\gamma_{r}\left(Q_{r}, Q_{e}\right)=\alpha_{e}\left(Q_{e}\right)-\beta_{e}\left(Q_{e}, Q_{r}\right)+\gamma_{e}\left(Q_{e}, Q_{r}\right)=P\left(\Omega_{2}+\Omega_{3}+\Omega_{4}\right)$

After substituting the equations in Table 2 into the first-order conditions of Equations (10) and (11), and rearranging, we obtain

$$
F_{e}\left(Q_{e}^{T}\right)=\frac{p+l-r-c}{p+l-r-s}+\frac{\tau-s}{p+l-r-s} \beta_{e}\left(Q_{e}^{T}, Q_{r}^{T}\right)-\frac{p+l-r-\tau}{p+l-r-s} \gamma_{e}\left(Q_{e}^{T}, Q_{r}^{T}\right)
$$




$$
F_{r}\left(Q_{r}^{T}\right)=\frac{p+l-w}{p+l-s}+\frac{\tau+r-s}{p+l-s} \beta_{r}\left(Q_{r}^{T}, Q_{e}^{T}\right)-\frac{p+l-\tau}{p+l-s} \gamma_{r}\left(Q_{r}^{T}, Q_{e}^{T}\right)
$$

Comparing Equations (6) and (12), we find that their left-hand sides are the same cumulative probability distribution in two scenarios. On the right-hand sides, the first terms are same respectively; the second terms increase $Q_{e}^{T}$ due to the possibility of transshipment from store $e$ to $r$; the third term decreases $Q_{e}^{T}$ due to the possibility of transshipment from store $r$ to $e$. In the same way, we can obtain similar results hold for the comparison of (7) and (13). For a continuous demand distribution, the optimal inventory level $Q_{i}^{T}$ increases with the value of the right-hand sides of Equations (12) and (13)

Proposition 3. With transshipment, there exists a unique Nash equilibrium in the two stores' ordering decision.

Proposition 4. With transshipment, the unique optimal order quantities $\left(Q_{r}^{T *}, Q_{e}^{T *}\right)$ to maximize supply chain members' expected profits satisfy

$$
\left\{\begin{array}{l}
F_{e}\left(Q_{e}^{T}\right)=\frac{p+l-r-c}{p+l-r-s}+\frac{\tau-s}{p+l-r-s} \beta_{e}\left(Q_{e}^{T}, Q_{r}^{T}\right)-\frac{p+l-r-\tau}{p+l-r-s} \gamma_{e}\left(Q_{e}^{T}, Q_{r}^{T}\right) \\
F_{r}\left(Q_{r}^{T}\right)=\frac{p+l-w}{p+l-s}+\frac{\tau+r-s}{p+l-s} \beta_{r}\left(Q_{r}^{T}, Q_{e}^{T}\right)-\frac{p+l-\tau}{p+l-s} \gamma_{r}\left(Q_{r}^{T}, Q_{e}^{T}\right)
\end{array}\right.
$$

Proposition 5. With transshipments, both stores' optimal inventory order levels are increasing with the transshipment price, holding other cost parameters constant.

Proposition 5 states that when transshipment price increases, store $i$ spends more to transfer from store $j$ if he/she faces a stockout, and at the same time earns more if transfer to store $j$, both of which will encourage him/her to increase the optimal inventory order level.

Proposition 6. With transshipments, store $r$ 's optimal inventory order level is increasing with the revenue share, while store $e$ 's optimal inventory order level is decreasing with the revenue share, holding other cost parameters constant.

Combining Equations (8) and (9), we can obtain the total expected profit of the decentralized 
OTO supply chain is

$$
\pi^{T}\left(Q_{e}^{T}, Q_{r}^{T}\right)=E\left[p \min \left(D_{e}+D_{r}, Q_{e}^{T}+Q_{r}^{T}\right)+s\left(Q_{e}^{T}+Q_{r}^{T}-D_{e}-D_{r}\right)^{+}-l\left(D_{e}+D_{r}-Q_{e}^{T}-Q_{r}^{T}\right)^{+}\right]-c\left(Q_{r}^{T}+Q_{e}^{T}\right)
$$

The difference between Equations (1) and (14) is that the total expected profit of the decentralized OTO supply chain is a function of transshipment price according to Proposition 4.

Proposition 7. With transshipments, there exists a unique transshipment price to maximize the total profit of the OTO supply chain, and the optimal transshipment price $\tau^{*}$ satisfies $F_{D}\left[Q_{e}^{T}\left(\tau^{*}\right)+Q_{r}^{T}\left(\tau^{*}\right)\right]=\frac{p+l-c}{p+l-s}$, where $Q_{e}^{T}\left(\tau^{*}\right)$ and $Q_{r}^{T}\left(\tau^{*}\right)$ are the inventory order levels obtained from Proposition 4 at the optimal transshipment price.

Comparing with the centralized scenario, we find

$$
Q_{e}^{T}\left(\tau^{*}\right)+Q_{r}^{T}\left(\tau^{*}\right)=Q^{C^{*}}
$$

which means the total order quantity in a decentralized OTO supply chain with transshipment at optimal transshipment price is equal to that in a centralized OTO supply chain.

\section{Illustration Example}

To obtain additional managerial insights, meanwhile, avoid trivialities, we introduce a specific demand distribution, i.e., uniform distribution, to analyze the OTO supply chain in this section. Let unit selling price $p=10$, unit wholesale price $w=7$, unit manufacturing cost $c=5$, salvage value $s=4$, penalty of unmet demand $l=2$, and the revenue share $r=1$.

We assume that the two stores have the same demand distribution $D_{i} \sim U[0,100]$. In a centralized OTO supply chain, the total demand distribution is 


$$
F_{D}(d)= \begin{cases}\frac{1}{20000} d^{2} & \text { if } 0 \leq d<100 \\ \frac{1}{10000}\left(-\frac{1}{2} d^{2}+200 d-10000\right) & \text { if } 100 \leq d<200 \\ 1 & \text { otherwise }\end{cases}
$$

The probabilities defined in decentralized OTO supply chain are presented as follows

$$
\begin{aligned}
& F_{i}\left(Q_{i}\right)=\alpha_{i}\left(Q_{i}\right)= \begin{cases}\frac{1}{100} Q_{i} & \text { if } 0 \leq Q_{i}<100 \\
1 & \text { otherwise }\end{cases} \\
& \beta_{i}\left(Q_{i}, Q_{j}\right)= \begin{cases}\frac{1}{10000}\left(100 Q_{i}-Q_{i} Q_{j}-\frac{1}{2} Q_{i}^{2}\right) & \text { if } 0<Q_{j}<100-Q_{i} \\
\frac{1}{20000}\left(100-Q_{j}\right)^{2} & \text { if } 100-Q_{i} \leq Q_{j}<100 \\
0 & \text { otherwise }\end{cases} \\
& \gamma_{i}\left(Q_{i}, Q_{j}\right)= \begin{cases}\frac{1}{20000} Q_{j}^{2} & \text { if } 0<Q_{j}<100-Q_{i} \\
\frac{1}{20000}\left(100-Q_{i}\right)\left(2 Q_{j}+Q_{i}-100\right) & \text { if } 100-Q_{i} \leq Q_{j}<100 \\
\frac{1}{20000}\left[\left(100-Q_{i}\right)\left(2 Q_{j}+Q_{i}-100\right)\right. & \text { if } 100 \leq Q_{j}<200-Q_{i} \\
- & \text { otherwise }\end{cases}
\end{aligned}
$$

From the previous section, it is easy to know the transshipment price has an influence on the inventory order levels of each store. We vary transshipment price from 4 to 12 . Note that according to the assumptions and set of parameters, we know $4<\tau<11$, thus $\tau=4, \tau=11$, $\tau=12$ are only employed for the sake of comparison. Figures 3(a) -3(f) present the inventory order level response functions for the two stores, respectively.
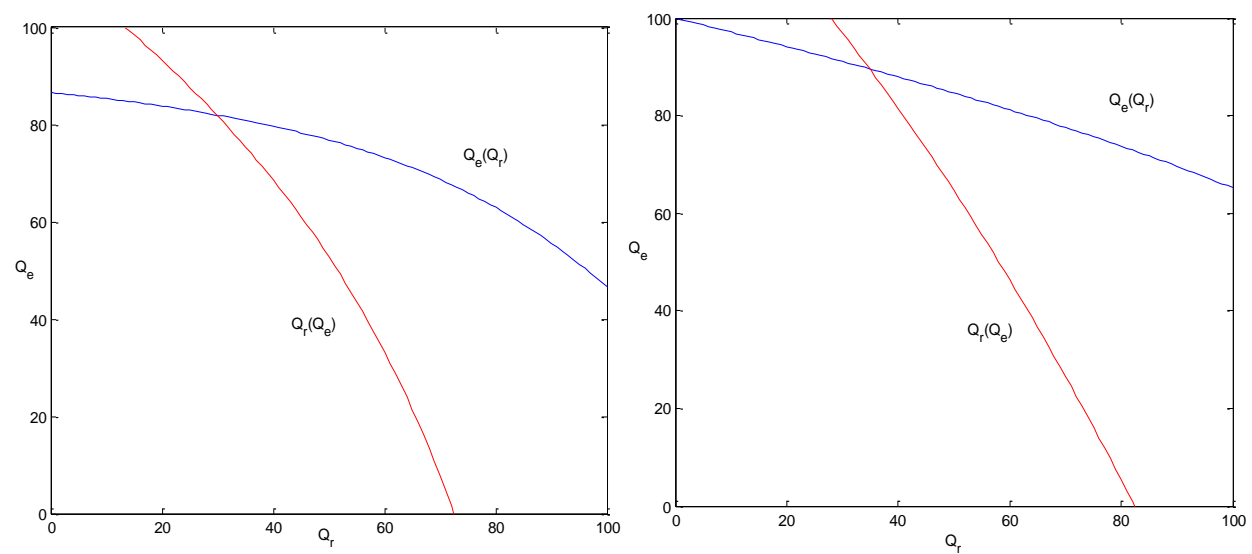
Fig. 3(a) Order level response functions with $\tau=4$

Fig. 3(b) Order level response functions with $\tau=6$
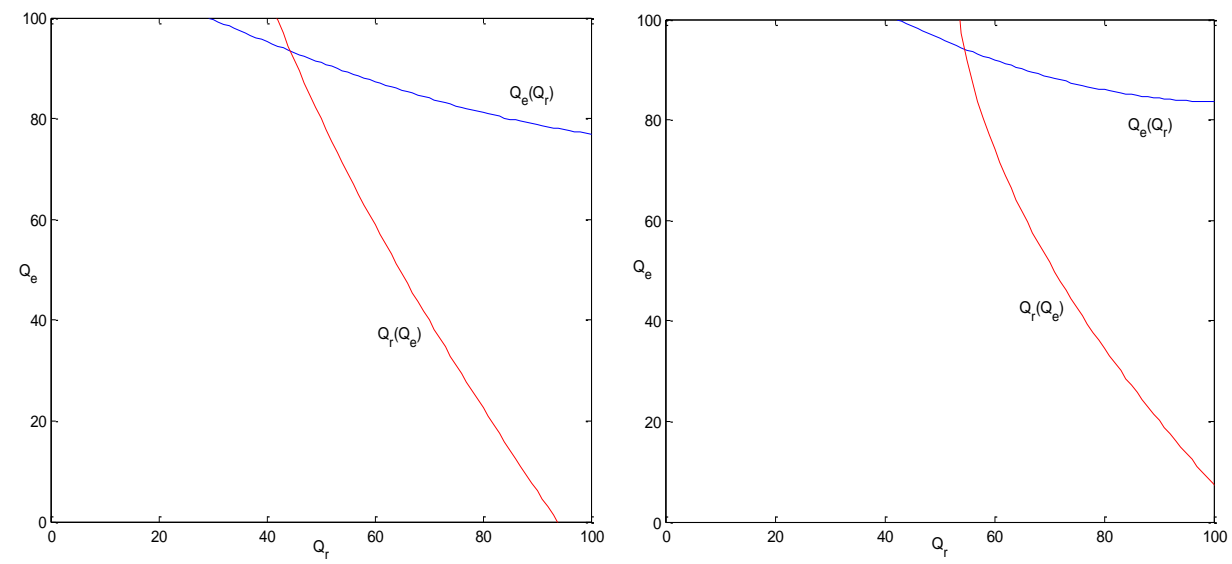

Fig. 3(c) Order level response functions with $\tau=8$

Fig. 3(d) Order level response functions with $\tau=10$
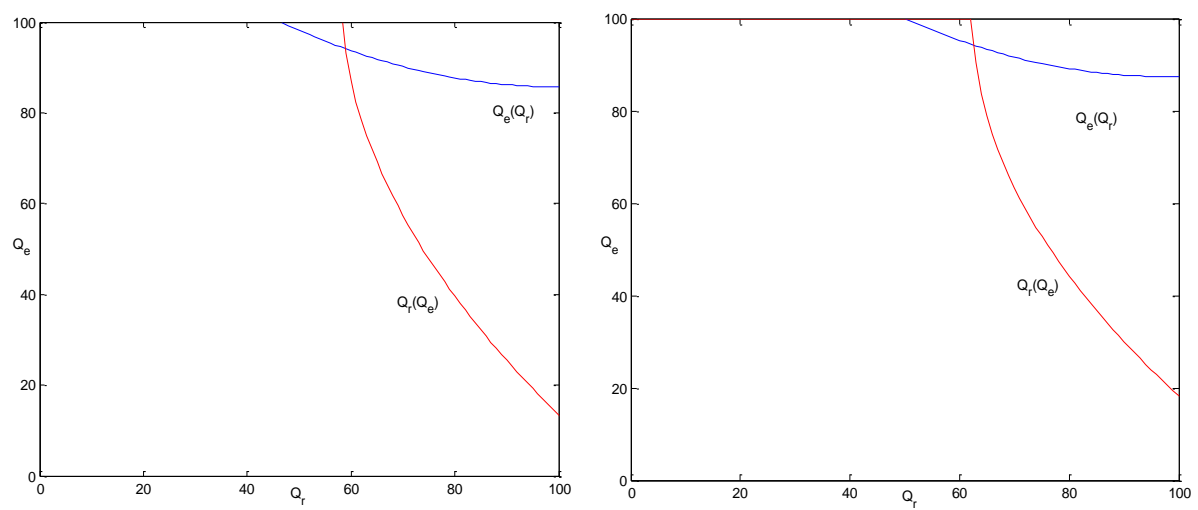

Fig. 3(e) Order level response functions with $\tau=11$

Fig. 3(f) Order level response functions with $\tau=12$

Observation 1. The inventory order level response function $Q_{i}\left(Q_{j}\right)$ is a decreasing function. When transshipment price is low, $Q_{i}\left(Q_{j}\right)$ is concave; when $Q_{j}$ is large, $Q_{i}\left(Q_{j}\right)$ is convex.

The reasons for Observation 1 are as follows. When store $j$ increases inventory order level, it reduces the possibility of transshipment from store $i$, and store $i$ can transfer from store $j$ in case of stockout, thus there is no necessary for store $i$ to increase inventory order level. Especially when the transshipment price is low, store $i$ will decrease more order quantity and vice versa.

Observation 2. There exists a unique intersection of $Q_{i}\left(Q_{j}\right)$ and $Q_{j}\left(Q_{i}\right)$. 
Observation 2 is in line with Proposition 3. Combining Equations (12), (13) and (15), we can get the optimal transshipment price $\tau^{*}=10.29$ to maximize the profit of the entire supply chain. The optimal order quantities and expected profits at different transshipment prices are illustrated in Table 4.

Table 4. Sensitivity analysis of transshipment price for each member

\begin{tabular}{cccccc}
\hline Scenario & \multicolumn{3}{c}{ Manufacturer } & \multicolumn{2}{c}{ Retailer } \\
\hline \multirow{2}{*}{$\begin{array}{c}\text { Without } \\
\text { Transshipment }\end{array}$} & $Q_{e}^{N}$ & $\pi_{m}^{N}$ & $\pi_{e}^{N}$ & $Q_{r}^{N}$ & $\pi_{r}^{N}$ \\
\cline { 2 - 6 } & 85.71 & 282.14 & 157.14 & 62.50 & 105.23 \\
\hline With & $Q_{e}^{T}$ & $\pi_{m}^{T}$ & $\pi_{e}^{T}$ & $Q_{r}^{T}$ & $\pi_{r}^{T}$ \\
Transshipment & & & & & \\
\hline$\tau=4$ & 81.97 & 218.96 & 159.36 & 29.80 & 177.69 \\
$\tau=6$ & 89.57 & 255.99 & 186.27 & 34.86 & 162.04 \\
$\tau=8$ & 93.38 & 290.44 & 201.62 & 44.41 & 139.66 \\
$\tau=10$ & 94.13 & 312.80 & 201.66 & 54.57 & 120.50 \\
$\boldsymbol{\tau}=\mathbf{1 0 . 2 9}$ & $\mathbf{9 4 . 1 4}$ & $\mathbf{3 1 5 . 1 0}$ & $\mathbf{2 0 3 . 3 8}$ & $\mathbf{5 5 . 8 6}$ & $\mathbf{1 1 8 . 2 4}$ \\
$\tau=11$ & 94.15 & 320.01 & 202.17 & 58.92 & 113.13 \\
$\tau=12$ & 94.20 & 325.24 & 200.00 & 62.62 & 107.00 \\
\hline & & & & & \\
& & & & & \\
\hline
\end{tabular}

Observation 4. Compared with the OTO supply chain without transshipment, the manufacturer is worse off at low transshipment price and better off at higher transshipment price with transshipment; while the retailer is always better off by transshipment.

Observation 4 implies that when transshipment price is low, both stores reduce their inventory order levels. The wholesale part of the manufacturer's expected profit also decrease due to the order quantity decline from the retailer, thus the manufacturer's total expected profit decrease more. When $\tau=4$, the manufacturer's expected profit is even less than that without transshipment; When 
$\tau=11$ and $\tau=12$, both parties' expected profits begin to decrease, even though their inventory order levels increase, which is in accordance with our assumption, i.e., $s<\tau<p+l-s$.

We present the optimal order quantities and expected profits of the whole OTO supply chain in different scenarios in Table 5.

Table 5. Sensitivity analysis of transshipment price for the entire supply chain

\begin{tabular}{ccc}
\hline Scenario & Order level & Profit \\
\hline $\begin{array}{c}\text { Centralized } \\
\text { OTO }\end{array}$ & $Q^{C}$ & $\pi^{C}$ \\
\cline { 2 - 3 } & 150 & 700 \\
\hline Without & $Q^{N}$ & $\pi^{N}$ \\
\cline { 2 - 3 } Transshipment & 148.21 & 387.37 \\
\hline With & $Q^{T}$ & $\pi^{T}$ \\
\cline { 2 - 3 }$\tau=4$ & 111.77 & 396.65 \\
$\tau=6$ & 124.43 & 418.03 \\
$\tau=8$ & 137.79 & 430.10 \\
$\tau=10$ & 148.70 & 433.30 \\
$\tau=10.29$ & $\mathbf{1 5 0 . 0 0}$ & $\mathbf{4 3 3 . 3 4}$ \\
$\tau=11$ & 154.07 & 433.14 \\
$\tau=12$ & 156.82 & 432.24 \\
\hline
\end{tabular}

Observation 4. The total expected profit of the whole supply chain with transshipment is larger than that without transshipment, i.e., lateral inventory transshipment always benefit the whole OTO supply chain.

When $\tau=10.29, Q^{T^{*}}=Q^{C^{*}}$, but $\pi^{T^{*}}<\pi^{C^{*}}$, i.e., the maximal total expect profit of a decentralized OTO supply chain is still much less than that in centralized OTO supply chain. We 
then vary the revenue share $r$, holding the transshipment price $\tau=8$ and other parameters constant. Tables 6 and 7 present the optimal inventory order levels and expected profits.

Table 6. Sensitivity analysis of revenue share for each member

\begin{tabular}{cccccc}
\hline Scenario & \multicolumn{3}{c}{ Manufacturer } & \multicolumn{2}{c}{ Retailer } \\
\hline $\begin{array}{c}\text { Without } \\
\text { Transshipment }\end{array}$ & $Q_{e}^{N}$ & $\pi_{m}^{N}$ & $\pi_{e}^{N}$ & $Q_{r}^{N}$ & $\pi_{r}^{N}$ \\
\cline { 2 - 6 } & 85.71 & 282.14 & 157.14 & 62.50 & 105.23 \\
\hline $\begin{array}{c}\text { With } \\
\text { Transshipment }\end{array}$ & $Q_{e}^{T}$ & $\pi_{m}^{T}$ & $\pi_{e}^{T}$ & $Q_{r}^{T}$ & $\pi_{r}^{T}$ \\
\hline$r=0.5$ & 93.76 & 315.16 & 226.66 & 44.25 & 118.43 \\
$r=1$ & 93.38 & 290.44 & 201.62 & 44.41 & 139.66 \\
$r=1.5$ & 92.94 & 266.16 & 176.96 & 44.60 & 164.35 \\
$r=2$ & 92.45 & 240.82 & 151.18 & 44.82 & 189.00 \\
$r=2.5$ & 91.87 & 216.52 & 126.34 & 45.09 & 213.57 \\
\hline
\end{tabular}

Table 7. Sensitivity analysis of revenue share for the entire supply chain

\begin{tabular}{ccc}
\hline Scenario & Order level & Profit \\
\hline $\begin{array}{c}\text { Centralized } \\
\text { OTO }\end{array}$ & $Q^{C}$ & $\pi^{C}$ \\
\cline { 2 - 3 } & 150 & 700 \\
\hline $\begin{array}{c}\text { Without } \\
\text { Transshipment }\end{array}$ & $Q^{N}$ & $\pi^{N}$ \\
\cline { 2 - 3 } With & 148.21 & 387.37 \\
Transshipment & $Q^{T}$ & $\pi^{T}$ \\
\cline { 2 - 3 }$r=0.5$ & 138.01 & 433.59 \\
$r=1$ & 137.79 & 430.10 \\
$r=1.5$ & 137.54 & 430.51 \\
$r=2$ & 137.27 & 429.82 \\
\hline
\end{tabular}




$r=2.5 \quad 136.96 \quad 430.09$

Observation 5. The retailer's expected profit with transshipment increases with the revenue share and the manufacturer's expected profit with transshipment decreases with the revenue share. However, they are both better off than that without transshipment.

Our results show that revenue share can coordinate the OTO supply chain and reallocate the total profit. The optimal revenue share depends on the dominant bargaining power of both parties. Since retail is the main source of both stores' expected profits, revenue share has only a small effect on the optimal inventory order levels, irrespective of other parameters.

Observation 6. Compared with centralized OTO supply chain, the total expected profit is always less in a decentralized OTO supply chain with/without transshipment.

This phenomenon can be attributed to the double marginalization, which demonstrates Proposition 2. In reality, it costs a lot to manage a brick-and-mortar store, e.g., administrative cost, rental cost and human resource cost. Consider these costs as $C$, the manufacturer needs to weigh $\pi^{C}-C$ and $\pi_{m}^{T}$, and decides whether to employ centralized or decentralized OTO supply chain.

\section{Conclusions}

This paper studies a new e-commercial model, i.e., Online-to-Offline, in dual-channel supply chain. To reduce the inventory risk caused by demand uncertainty of each channel, we employ lateral inventory transshipment between the e-store and brick-and-mortar store. Since all the inventories are deposited in the brick-and-mortar store's warehouse, there exists no transshipment cost and it is much more convenient to carry out the transshipment. We model the centralized OTO and decentralized OTO with/without inventory transshipment.

We then adopt uniform demand distribution to obtain more managerial insights. We find that transshipment can always benefit the supply chain, and revenue share $r$ reallocates the total expected profit, but has a small effect on the inventory order levels of both channels. There exists a unique transshipment price to maximize the profit of the entire supply chain. Our conclusions can 
also be applied to general demand distribution and the cases with correlative demands, which just brings trivialities and there is no more insights.

There are some interesting and important issues can be studied for future research. For example, we can consider multiple retailers, in which the manufacturer can choose other retailers to deliver when he faces a stockout in the nearest retailer, instead of transshipment, if the transshipment price is high. Another future research area might also explore the difference lateral transshipment prices between the two channels in OTO supply chain. Finally, it would be interesting to study the different channel prices with customer switching in OTO supply chain.

\section{Appendix}

\section{Proof of Proposition 1.}

Since $F_{i}(\cdot)$ is an increasing function on its support, the two conclusions of Proposition 1 can be easily obtained from Equations (6) and (7).

\section{Proof of Proposition 2.}

From the property of inverse function, we obtain $F_{e}^{-1}\left(\frac{p-r+l-c}{p-r+l-s}\right)<F_{e}^{-1}\left(\frac{p+l-c}{p+l-s}\right)$ and $F_{r}^{-1}\left(\frac{p+l-w}{p+l-s}\right)<F_{r}^{-1}\left(\frac{p+l-c}{p+l-s}\right)$, thus $F_{e}^{-1}\left(\frac{p-r+l-c}{p-r+l-s}\right)+F_{r}^{-1}\left(\frac{p+l-w}{p+l-s}\right)<F_{e}^{-1}\left(\frac{p+l-c}{p+l-s}\right)+F_{r}^{-1}\left(\frac{p+l-c}{p+l-s}\right)=F_{D}^{-1}\left(\frac{p+l-c}{p+l-s}\right)$, i.e., $Q_{e}^{N^{*}}+Q_{r}^{N^{*}}<Q^{C^{*}}$.

\section{Proof of Proposition 3.}

Substituting the definitions in Table 2 into Equations (10) and (11), we can obtain

$$
\begin{aligned}
& \frac{\partial \pi_{m}^{T}}{\partial Q_{e}^{T}}=-(p+l-s-r) \alpha_{e}\left(Q_{e}\right)+(\tau-s) \beta_{e}\left(Q_{e}, Q_{r}\right)-(p+l-\tau-r) \gamma_{e}\left(Q_{e}, Q_{r}\right)+p+l-c-r \\
& \frac{\partial \pi_{r}^{T}}{\partial Q_{r}^{T}}=-(p+l-s) \alpha_{r}\left(Q_{r}\right)+(\tau+r-s) \beta_{r}\left(Q_{r}, Q_{e}\right)-(p+l-\tau) \gamma_{r}\left(Q_{r}, Q_{e}\right)+p+l-w
\end{aligned}
$$


As we define, the functions $\alpha_{i}\left(Q_{i}\right), \beta_{i}\left(Q_{i}, Q_{j}\right)$ and $\gamma_{i}\left(Q_{i}, Q_{j}\right)$ are continuous and differentiable in $Q_{i}$ and $Q_{j}$. We denote the marginal probabilities as the first column in Table 8, thus the results in the second column hold (Rudi et al. 2001).

Table 8. The definitions of the marginal probabilities and the corresponding results

\begin{tabular}{l|l}
\hline Definitions & Results \\
\hline$g_{i}=f_{D_{i}}\left(Q_{i}\right)$ & $\frac{\partial \alpha_{i}}{\partial Q_{i}}=g_{i}$ \\
$m_{i j}^{1}=P\left(D_{i}<Q_{i}\right) f_{D_{i}+D_{j} \mid D_{i}<Q_{i}}\left(Q_{i}+Q_{j}\right)$ & $\frac{\partial \beta_{i}}{\partial Q_{i}}=-m_{i j}^{1}+m_{i j}^{2}$ \\
$m_{i j}^{2}=P\left(D_{i}+D_{j}>Q_{i}+Q_{j}\right) f_{D_{i} \mid D_{i}+D_{j}>Q_{i}+Q_{j}}\left(Q_{i}\right)$ & $\frac{\partial \beta_{i}}{\partial Q_{j}}=-m_{i j}^{1}$ \\
$n_{i j}^{1}=P\left(D_{i}>Q_{i}\right) f_{D_{i}+D_{j} \mid D_{i}>Q_{j}}\left(Q_{i}+Q_{j}\right)$ & $\frac{\partial \gamma_{i}}{\partial Q_{i}}=n_{i j}^{1}-n_{i j}^{2}$ \\
$n_{i j}^{2}=P\left(D_{i}+D_{j}<Q_{i}+Q_{j}\right) f_{D_{i} \mid D_{i}+D_{j}<Q_{i}+Q_{j}}\left(Q_{i}\right)$ & $\frac{\partial \gamma_{i}}{\partial Q_{j}}=n_{i j}^{1}$ \\
\hline
\end{tabular}

Taking the second orders of the expected profits functions with respect to $Q_{e}^{T}$ and $Q_{r}^{T}$, respectively, and substituting the definitions in Table 3 into the results, yields

$$
\begin{aligned}
& \frac{\partial^{2} \pi_{m}^{T}}{\partial\left(Q_{e}^{T}\right)^{2}}=-(p+l-s-r) g_{e}-(\tau-s)\left(m_{e r}^{1}-m_{e r}^{2}\right)-(p+l-\tau-r)\left(n_{e r}^{1}-n_{e r}^{2}\right) \\
& \frac{\partial^{2} \pi_{r}^{T}}{\partial\left(Q_{r}^{T}\right)^{2}}=-(p+l-s) g_{r}-(\tau+r-s)\left(m_{r e}^{1}-m_{r e}^{2}\right)-(p+l-\tau)\left(n_{r e}^{1}-n_{r e}^{2}\right)
\end{aligned}
$$

Given the parameter assumptions and definitions, it is easy to check that $\frac{\partial^{2} \pi_{m}^{T}}{\partial\left(Q_{e}^{T}\right)^{2}}<0$ and $\frac{\partial^{2} \pi_{r}^{T}}{\partial\left(Q_{r}^{T}\right)^{2}}<0$. Given store $i$ 's inventory level $Q_{i}^{T}, \pi_{j}^{T}$ is concave in $Q_{j}^{T} \quad(i, j=r, e ; i \neq j)$.

Thus there exists a unique Nash equilibrium solution.

\section{Proof of Proposition 4.}


The inventory choice $\left(Q_{r}^{T *}, Q_{e}^{T *}\right)$ maximizing profit can be obtained by setting the expected marginal benefit to zero. Combining the first-order condition of Equations (12) and (13), yields

$$
\left\{\begin{array}{l}
F_{e}\left(Q_{e}^{T}\right)=\frac{p+l-r-c}{p+l-r-s}+\frac{\tau-s}{p+l-r-s} \beta_{e}\left(Q_{e}^{T}, Q_{r}^{T}\right)-\frac{p+l-r-\tau}{p+l-r-s} \gamma_{e}\left(Q_{e}^{T}, Q_{r}^{T}\right) \\
F_{r}\left(Q_{r}^{T}\right)=\frac{p+l-w}{p+l-s}+\frac{\tau+r-s}{p+l-s} \beta_{r}\left(Q_{r}^{T}, Q_{e}^{T}\right)-\frac{p+l-\tau}{p+l-s} \gamma_{r}\left(Q_{r}^{T}, Q_{e}^{T}\right)
\end{array}\right.
$$

\section{Proof of Proposition 5.}

Since $F_{i}(\cdot)$ is an increasing function on its support, Proposition 5 can be easily obtained from the right-hands of Equations (12) and (13).

\section{Proof of Proposition 6.}

Since $F_{i}(\cdot)$ is an increasing function on its support, Proposition 6 can be easily obtained from the right-hands of Equations (12) and (13).

\section{Proof of Proposition 7.}

Taking the first orders of Equation (14) with respect to $Q_{e}^{T}, Q_{r}^{T}$ and $\tau$, respectively, we obtain $\frac{\partial \pi^{T}}{\partial Q_{e}^{T}}=\frac{\partial \pi^{T}}{\partial Q_{r}^{T}}=(p+l) P\left(\Omega_{1}+\Omega_{5}+\Omega_{6}\right)+s P\left(\Omega_{2}+\Omega_{3}+\Omega_{4}\right)-c=p+l-c-(p+l-s) F_{D}\left(Q_{e}^{T}+Q_{r}^{T}\right)$ and $\frac{\partial \pi^{T}}{\partial \tau}=\frac{\partial \pi^{T}}{\partial Q_{e}^{T}} \frac{\partial Q_{e}^{T}}{\partial \tau}+\frac{\partial \pi^{T}}{\partial Q_{r}^{T}} \frac{\partial Q_{r}^{T}}{\partial \tau}=\left[(p+l-c)-(p+l-s) F_{D}\left(Q_{e}^{T}+Q_{r}^{T}\right)\right]\left(\frac{\partial Q_{e}^{T}}{\partial \tau}+\frac{\partial Q_{r}^{T}}{\partial \tau}\right)$. It is known from Proposition 5 that $\frac{\partial Q_{e}^{T}}{\partial \tau}>0$ and $\frac{\partial Q_{r}^{T}}{\partial \tau}>0$. Notice $\pi^{T}$ is continuous under our assumptions in this paper, when $p+l-c>(p+l-s) F_{D}\left(Q_{e}^{T}+Q_{r}^{T}\right), \frac{\partial \pi^{T}}{\partial \tau}>0$, and when $p+l-c<(p+l-s) F_{D}\left(Q_{e}^{T}+Q_{r}^{T}\right), \frac{\partial \pi^{T}}{\partial \tau}<0$. Thus $\pi^{T}$ is concave in $\tau$. Letting the first order to be zero, we get the unique optimal total profit condition $F_{D}\left(Q_{e}^{T^{*}}+Q_{r}^{T *}\right)=\frac{p+l-c}{p+l-s}$. 


\section{Reference}

Archibald T W, Black D, Glazebrook K D. 2009. An index heuristic for transshipment decisions in multi-location inventory systems based on a pairwise decomposition[J]. European Journal of Operational Research, 192(1): 69-78.

Ayanso A, Diaby M, Nair S K. 2006. Inventory rationing via drop-shipping in Internet retailing: A sensitivity analysis[J]. European Journal of Operational Research, 171(1): 135-152.

Belgasmi N, Said L B, Ghédira K. 2008. Evolutionary multiobjective optimization of the multilocation transshipment problem[J]. Operational Research, 8(2): 167-183.

Chen K Y, Kaya M, Özer Ö. 2008. Dual sales channel management with service competition[J]. Manufacturing \& Service Operations Management, 10(4): 654-675.

Chen, X., Hao, G., Li, X., Yiu, K. F. C. 2012. The impact of demand variability and transshipment on vendor's distribution policies under vendor managed inventory strategy. International Journal of Production Economics, 139(1), 42-48.

Chiang W K, Chhajed D, Hess J D. 2003. Direct marketing, indirect profits: A strategic analysis of dual-channel supply-chain design[J]. Management science, 49(1): 1-20.

Dodd, D., 2001. Tesco corners the online grocery market. Financial Times, San Francisco, Feb 1.

Dong L, Rudi N. 2004. Who benefits from transshipment? Exogenous vs. endogenous wholesale prices[J]. Management Science, 50(5): 645-657.

Gan X, Sethi S P, Zhou J. 2010. Commitment-penalty contracts in drop-shipping supply chains with asymmetric demand information[J]. European Journal of Operational Research, 204(3): 449462 .

He Y, Zhang P, Yao Y. 2014. Unidirectional transshipment policies in a dual-channel supply chain[J]. Economic Modelling, 40: 259-268.

Hezarkhani B, Kubiak W. 2010. A coordinating contract for transshipment in a two-company supply chain[J]. European Journal of Operational Research, 207(1): 232-237.

Hovelaque V, Soler L G, Hafsa S. 2007. Supply chain organization and e-commerce: a model to analyze store-picking, warehouse-picking and drop-shipping[J]. 4OR, 5(2): 143-155.

Hu X, Duenyas I, Kapuscinski R. 2007. Existence of coordinating transshipment prices in a twolocation inventory model[J]. Management Science, 53(8): 1289-1302.

Hu X, Duenyas I, Kapuscinski R. 2008. Optimal joint inventory and transshipment control under uncertain capacity[J]. Operations Research, 56(4): 881-897. 
Huang S, Yang C, Zhang X. 2012. Pricing and production decisions in dual-channel supply chains with demand disruptions[J]. Computers \& Industrial Engineering, 62(1): 70-83.

Khouja M. 2001. The evaluation of drop shipping option for e-commerce retailers[J]. Computers \& industrial engineering, 41(2): 109-126.

Khouja M, Stylianou A C. 2009. A (Q, R) inventory model with a drop-shipping option for ebusiness[J]. Omega, 37(4): 896-908.

Koulamas C. 2006. A Newsvendor Problem with Revenue Sharing and Channel Coordination[J]. Decision Sciences, 37(1): 91-100.

Li M, Zhang J. 2012. Does inventory pooling improve customer service levels? [J]. Operations Research Letters, 40(2): 96-98.

Lien, R. W., Iravani, S. M., Smilowitz, K., Tzur, M. 2011. An efficient and robust design for transshipment networks. Production and Operations Management, 20(5), 699-713.

Netessine S, Rudi N. 2006. Supply chain choice on the internet[J]. Management Science, 52(6): 844-864.

Özdemir D, Yücesan E, Herer Y T. 2013. Multi-location transshipment problem with capacitated production[J]. European Journal of Operational Research, 226(3): 425-435.

Paterson C, Kiesmüller G, Teunter R, Glazebrook, K. 2011. Inventory models with lateral transshipments: A review[J]. European Journal of Operational Research, 210(2): 125-136.

Paterson C, Teunter R, Glazebrook K. 2012. Enhanced lateral transshipments in a multi-location inventory system[J]. European Journal of Operational Research, 221(2): 317-327.

Rabinovich E, Rungtusanatham M, Laseter T M. 2008. Physical distribution service performance and internet retailer margins: The drop-shipping context[J]. Journal of Operations Management, 26(6): 767-780.

Randall T, Netessine S, Rudi N. 2006. An empirical examination of the decision to invest in fulfillment capabilities: A study of Internet retailers[J]. Management Science, 52(4): 567-580.

Robinson L W. 1990. Optimal and approximate policies in multiperiod, multilocation inventory models with transshipments[J]. Operations Research, 38(2): 278-295.

Rudi N, Kapur S, Pyke D F. 2001. A two-location inventory model with transshipment and local decision making[J]. Management science, 47(12): 1668-1680.

Seifert R W, Thonemann U W, Sieke M A. 2006. Relaxing channel separation: Integrating a virtual store into the supply chain via transshipments[J]. Iie Transactions, 38(11): 917-931. 
Tagaras G, Vlachos D. 2002. Effectiveness of stock transshipment under various demand distributions and nonegligible transshipment times [J]. Production and Operations Management, 11(2): 183-198.

Tsay A A, Agrawal N. 2004. Channel Conflict and Coordination in the E-Commerce Age[J]. Production and Operations Management, 13(1): 93-110.

Yao D Q, Kurata H, Mukhopadhyay S K. 2008. Incentives to reliable order fulfillment for an Internet drop-shipping supply chain[J]. International Journal of Production Economics, 113(1): 324-334.

Yang J, Qin Z. 2007. Capacitated production control with virtual lateral transshipments[J]. Operations research, 55(6): 1104-1119.

Yu D Z, Tang S Y, Niederhoff J. 2011. On the benefits of operational flexibility in a distribution network with transshipment[J]. Omega, 39(3): 350-361.

Zhang J. 2005. Transshipment and its impact on supply chain members' performance[J]. Management Science, 51(10): 1534-1539.

Zou L, Dresner M, Windle R. 2010. A two-location inventory model with transshipments in a competitive environment[J]. International Journal of Production Economics, 125(2): 235-250. 